\title{
Parental restriction reduces the harmful effects of in- bedroom electronic devices
}

\author{
King-wa Fu, ${ }^{1}$ Frederick Ka Wing Ho, ${ }^{2}$ Nirmala Rao, ${ }^{3}$ Fan Jiang, ${ }^{4}$ Sophia Ling Li, ${ }^{2}$ \\ Tatia Mei-chun Lee, ${ }^{5,6}$ Sophelia Hoi-shan Chan, ${ }^{2}$ Ada Wing-yan Yung, ${ }^{2}$ \\ Mary Eming Young, ${ }^{7}$ Patrick $I p^{2}$
}

- Additional material is published online only. To view please visit the journal online (http://dx.doi.org/10.1136/ archdischild-2017-312639).

1Journalism and Media Studies Centre, The University of Hong Kong, Pok Fu Lam, Hong Kong ${ }^{2}$ Department of Paediatrics and Adolescent Medicine, The University of Hong Kong, Pok Fu Lam, Hong Kong

${ }^{3}$ Faculty of Education, The University of Hong Kong, Pok Fu Lam, Hong Kong

${ }^{4}$ Shanghai Children's Medical

Center, Shanghai, People's

Republic of China

${ }^{5}$ Laboratory of Neuropsychology, The University of Hong Kong

Pok Fu Lam, Hong Kong

${ }^{6}$ State Key Laboratory of Brain

and Cognitive Sciences, The

University of Hong Kong, Pok Fu

Lam, Hong Kong

${ }^{7}$ China Development Research

Foundation, Beijing, China

\section{Correspondence to}

Dr Patrick Ip, Department of

Paediatrics and Adolescent

Medicine, The University of

Hong Kong, 1/F, New Clinical

Building, Queen Mary Hospital,

Hong Kong; patricip@hku.hk

K-F and FKWH contributed equally.

Received 5 January 2017 Revised 14 May 2017

Accepted 16 May 2017

Published Online First

29 June 2017

\begin{abstract}
Objective To investigate whether school readiness could be affected by placing electronic devices (EDs) in children's bedroom and whether the relationship was moderated by parental restriction and family socioeconomic status (SES).
\end{abstract}

Design This is a cross-sectional study with bedroom ED placement and parental restriction reported by parents. Multiple linear regressions were used to test the relationship between school readiness and ED placement. Multiple regression with interaction terms were used to test whether the effect was consistent with and without parental restriction.

Setting Kindergartens randomly selected from two districts of different socioeconomic backgrounds in Hong Kong, China.

Patients 556 young children attending the third year of kindergarten.

Main outcome measures Children's school readiness was rated by teachers using the Chinese Early Development Instrument.

Results 556 preschoolers (mean age 5.46; 51.8\% girls) from 20 kindergartens participated in this study. About $30 \%$ of parents placed at least one ED in their children's bedroom. After controlling for sex and SES, the placement of television in the bedroom was associated with lower overall school readiness $(\beta-1.11,95 \% \mathrm{Cl}$ -1.80 to -0.42 ) and the placement of game console was associated with lower social competence $(\beta-0.94$, $95 \% \mathrm{Cl}-1.74$ to -0.15$)$. Such harmful effect was more prominent among lower SES families and could be partially alleviated with parental restriction.

Conclusion ED placement in children's bedroom was associated with lower school readiness, particularly among lower SES families. Parental restriction might help to alleviate the harm.

\section{BACKGROUND}

In recent years, young children not only have access to traditional electronic devices (EDs) but also to more advanced ones, such as computers, smartphones and game consoles. ${ }^{1}$ The increasing access to EDs in early childhood also raised widespread concerns about their potential harm on child development. ${ }^{2}$ Television, being invented for decades, is the most widely studied ED. Numerous studies have shown that prolonged television exposure in early childhood could be harmful to children's cognitive development, ${ }^{3}$ sociobehavioural skills ${ }^{4}$ and physical well-being. ${ }^{5}$ Nevertheless, the effects of other EDs are far less studied and the evidence so

\section{What is already known on this topic?}

Young children had increasing exposure to electronic devices.

- Placing television in children's bedroom was associated with poor academic performance, sleeping problems and higher risk of obesity.

\section{What this study adds?}

Electronic devices placed in children's bedroom was associated with lower school readiness.

- The association was moderated by family socioeconomic status and parental restriction.

- Parent-child recreation activity mediated the relationship between school readiness and placing an electronic device in the child's bedroom.

far varied. For example, a US infant cohort study ${ }^{6}$ identified a negative association between media use and language development, but another cohort study ${ }^{7}$ focusing on Hispanic toddlers in the USA concluded none. In fact, a recent systematic review ${ }^{8}$ has revealed that $56 \%$ of the evidence concerning television viewing reported null effect on cognitive development, $38 \%$ reported negative effect and $6 \%$ reported positive effect. This shows that simply studying the time spent on ED may not be sufficient to unveil the complex relationship.

Preliminary studies have shown that the placement of ED could be a strong yet overlooked risk factor for poor health and development. A cross-sectional survey in the USA has identified that preschool children who had a television in bedroom were more likely to be overweight after adjusting for television view time and other confounders. ${ }^{9}$ A systematic review also concluded that bedroom ED placement could affect children's sleep duration and quality. ${ }^{10}$ Nevertheless, none of these studies considered the effect of ED placement on preschoolers' school readiness, a comprehensive construct including cognitive, language and socioemotional development. Furthermore, these studies also omitted possible moderators (such as socioeconomic status (SES) and parental restriction on ED use) ${ }^{10}$ and mediators (such as parent-child interaction and sleep duration). ${ }^{11}$ 
The current study addresses this knowledge gap with the following aims: (1) to study the pattern of bedroom ED placement and parental restriction among Chinese preschool children, (2) to study whether bedroom ED placement may affect school readiness, (3) to understand whether the association between bedroom ED placement and school readiness, if any, was moderated by parental restriction and SES and (4) to explore the extent to which the effects of ED placement was mediated by parentchild interaction and sleep duration.

\section{METHODS}

\section{Study design}

This is a cross-sectional study recruiting 556 preschoolers from 20 kindergartens. These Chinese-speaking kindergartens were selected from two districts of Hong Kong with contrasting SES profiles: Hong Kong Island (HKI) as an affluent district and Yuen Long (YL) as an underprivileged district. In 2012, the median monthly family income of Hong Kong was US\$3149, while HKI was ranked top (US\$4240) and YL was ranked bottom (US\$2680). ${ }^{12}$ Twenty-two kindergartens were randomly selected from all preschools in the two districts, and 20 preschools (9 from HKI, 11 from YL) consented to participate.

\section{Participants}

With permission from the kindergarten principals, one 5 -year-old class was randomly chosen from each participating school. Parents of all children in the class were invited to join the study and provide written consent. This sample also participated in two other published studies on the socioeconomic gradients of school readiness $^{12}$ and the relationship between sleep duration and child development. ${ }^{13}$ In the present study, parents were asked to complete a questionnaire on family ownership of EDs, bedroom ED placement and parental restriction practice. Children's school readiness was rated by trained kindergarten teachers.

\section{Measures}

School readiness and the Chinese Early Development Instrument School readiness is an indicator of whether a child possesses the cognitive, social and emotional skills necessary for success in school and has been shown to predict long-term educational outcomes. ${ }^{14}{ }^{15}$ School readiness was measured using the Chinese Early Development Instrument (CEDI), which was based on the Early Development Instrument (EDI), a comprehensive teacher-rated scale. ${ }^{16}$ The CEDI was previously validated and shown reliable (Cronbach's $\alpha \geq 0.90$, except for physical well-being domain with $\alpha=0.70$ ) for Chinese children. ${ }^{17}$

The teacher most familiar with the child was asked to assess his/her school readiness using the CEDI. All 69 participating teachers received comprehensive training on how to use the instrument and were given a guide to help them understand, interpret and code the CEDI items. The training included a 1-day orientation workshop, hands-on trials and continuous support by PI, NR and the research team. Teachers' trial rating was compared with a gold standard before rating the study participants. Further guidance and training were provided if a teacher's trial rating was not consistent with the gold standard.

The CEDI rating scale contains 103 items that assess five developmental domains: physical health and well-being, social competence, emotional maturity, language and cognitive development and communication skills/general knowledge. Each of the five domains was scored on a scale from 0 to 10 , with a higher score indicating better performance in the measured developmental domain. The total CEDI score was calculated as the sum of the five domains giving a score from 0 to 50 .

\section{Family questionnaire}

Parents were asked to complete a questionnaire previously developed in a pilot study. ${ }^{17}$ It assesses family ownership of EDs, bedroom ED placement, parental restriction of EDs, family demographics, SES, parent-child interaction and sleep duration.

\section{Electronic devices}

Parents were asked about three types of EDs at home: televisions, computers (desktop, laptop, tablet) and gaming devices (home and portable consoles). For each of the three EDs, parents were also asked about: (1) whether the EDs were placed in the child's bedroom ('Are televisions, desktop/laptop computers, and game consoles placed in your child's bedroom?') and (2) whether the parents restrict the child's use in that ED ('Do you limit your child's time spent on (a) televisions, (b) computers, and (c) game consoles?').

\section{Family SES}

Family SES was considered as both a potential confounder and moderator in this study. Several key family SES indicators were assessed: maternal and paternal education, maternal and paternal occupation, family assets and adjusted family monthly income. These were aggregated into an SES index using principal component analysis with varimax rotation, a validated method to describe SES differences within a population. ${ }^{18} \mathrm{~A}$ higher value in the index indicated that the family had a higher SES. The SES index was categorised into three levels with tertiles as cut-offs in moderation analysis for easier understanding.

\section{Parent-child interaction}

Parent-child interaction was a potential mediator between school readiness and unrestricted bedroom ED placement. The Chinese Parent-Child Interaction Scale was used to access the weekly frequency of eight parent-child interactive activities in the past month: (1) reading, (2) drawing, (3) singing, (4) storytelling, (5) discussing news and current affairs and the learning of (6) Chinese characters, (7) English alphabets and (8) arithmetic/pre-mathematics. These items were scored on a 4-point Likert scale, with Recreation (1-5) and Learning (6-8) Activity subscales. A higher score indicates more frequent parent-child interaction. The scale has been validated and shown reliable in a Rasch analysis (internal consistency 0.82). ${ }^{19}$

\section{Sleep duration}

Sleep duration was also considered as a potential mediator and assessed with a parent-reported item on the average number of hours the child slept per day in the past week, including both daytime naps and night-time sleeps. Previous studies have found the parent-reported sleep duration to be valid and reliable. ${ }^{20}$

\section{Statistical analysis}

Associations between school readiness and bedroom ED placement were tested using multiple linear regressions after controlling for sex and family SES. Parent-child interaction was not controlled in this analysis because it was a potential mediator and controlling for mediators may mask the true association. To analyse the moderating effect, interaction variables were created between bedroom ED placement and the potential moderating variables (SES and parental restriction). The interaction variables were entered into a multiple regression along with bedroom ED 


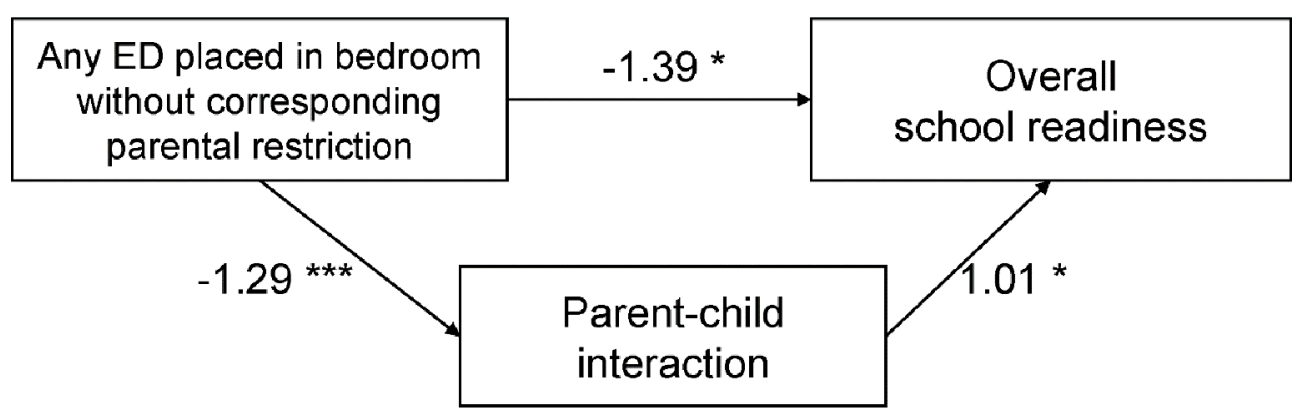

\begin{tabular}{lc}
\hline & $\beta(95 \%$ Cl) \\
\hline Total effect & $-2.70(-3.40 \text { to }-2.01)^{* *}$ \\
Mediated effect & $-1.31(-1.92 \text { to }-0.69)^{*}$ \\
Unmediated effect & $-1.39(-1.81$ to -0.98$)$ * \\
Proportion of mediation & $48.5 \%$ \\
\hline
\end{tabular}

Figure 1 Path model to explore the mechanism between electronic device (ED) use and children's school readiness, adjusted for sex and family socioeconomic status. These two variables are not shown in the figure for clarity. Model fit indices: Comparative Fit Index=0.96; Tucker-Lewis Index $=1.00$; root mean square error of approximation $(95 \% \mathrm{Cl})=0.00(0.00$ to 0.07$)$; standardised root mean square residual $=0.003$. ${ }^{*} p<0.05$, ${ }^{* *} p<0.01,{ }^{* *} p<0.001$

placement, family SES and sex. The statistical significance of the interaction variable indicates a moderator effect.

The mediation effects of SES, parent-child interaction and sleep duration were first tested by using Spearman's rank correlation coefficients because the ED variables were not normally distributed. Potential mediators that had significant correlation with ED variables were used in a path model (figure 1). A series of model fit indices were used to assess whether the model was appropriate for the data, including Comparative Fit Index (CFI), Tucker-Lewis Index (TLI), root mean square error of approximation (RMSEA) and standardised root mean square residual (SRMR). These indices use different approaches in assessing the model fit and therefore should be used simultaneously. ${ }^{21}$ A path model was accepted if its CFI and TLI were at least 0.96 , RMSEA at most 0.06 and SRMR at most $0.09 .^{21}$ The mediation effect was calculated using the Delta method with the lavaan package of the R Statistical Software. ${ }^{22}$ The statistical significance of the indirect effect indicates a mediator effect and the proportion of mediation showed the strength of mediation.

\section{Ethics approval}

The study was approved by the ethical committee of the Institutional Review Board of the University of Hong Kong/Hospital Authority Hong Kong West Cluster. Informed written consent was obtained from the parents of each participant.

\section{RESULTS}

\section{Descriptive statistics}

Parents of $575 \mathrm{~K} 3$ children from 20 kindergartens were invited and 567 agreed to participate $(98.6 \%$ response rate), of which 11 children having special educational needs were excluded. ${ }^{12}$ Characteristics of the remaining 556 participants are shown in table 1 . The mean (SD) age was $5.46(0.70)$ years and $288(51.8 \%)$ were female. Families on average owned 1.45 (0.73) televisions, 1.96 (0.93) computers, 0.51 (0.72) game consoles and 1.31 (0.91) smartphones. Median and IQR statistics were reported in the online supplementary table 1 . About one-third of the families placed at least one ED in the children's bedroom and the most common one was computer
$(114,20.5 \%)$. More than $80 \%$ of the families restricted children's use of either television, computer or game console, but only $71.6 \%$ restricted all three types of the EDs.

\section{School readiness and bedroom ED placement}

The associations between school readiness and ED placement are shown in table 2. Any ED placed in the children's bedroom was associated with worse social competence $(\beta-0.29,95 \% \mathrm{CI}$ -0.50 to -0.08$)$, emotional maturity $(\beta-0.19,95 \% \mathrm{CI}-0.35$ to -0.03$)$, language and cognitive skills $(\beta-0.24,95 \% \mathrm{CI}-0.39$ to -0.10$)$, communication/general knowledge $(\beta-0.26,95 \% \mathrm{CI}$ -0.50 to -0.03$)$ and overall school readiness $(\beta-1.11,95 \% \mathrm{CI}$ -1.80 to -0.42$)$. In addition, television and game console placed in the children's bedroom was associated with worse physical wellbeing $(\beta-0.37,95 \% \mathrm{CI}-0.59$ to -0.14$)$ and social competence $(\beta-0.94,95 \% \mathrm{CI}-1.74$ to -0.15$)$, respectively.

\section{Moderating roles of SES and parental restriction}

The correlation between family SES and EDs use is shown in table 3. Families with higher SES had more tablet computers $(\mathrm{r}=0.28, \mathrm{p}<0.001)$ but fewer portable game consoles $(\mathrm{r}=-0.31$, $\mathrm{p}<0.001)$. They were less likely to place EDs in the children's bedroom $(\mathrm{r}=-0.18, \mathrm{p}<0.01)$ and even less likely to allow ED use without parental restriction $(\mathrm{r}=-0.22, \mathrm{p}<0.001)$.

The effect of bedroom ED placement on a child's school readiness was moderated by family SES (figure $2 \mathrm{~A}$ ). Placing any ED in the children's bedroom significantly reduced children's overall school readiness by 2.26 (95\% CI 0.38 to 4.14 ) if they were from a lower SES family. The same effect was minimal and statistically insignificant for children in medium and higher SES families. The finding was similar for individual ED analysis.

The interaction of bedroom ED placement and parental restriction is shown in figure 2B. Placing any ED in the children's bedroom without corresponding parental restriction was significantly harmful to children's overall school readiness $(\beta-3.83,95 \% \mathrm{CI}$ -5.91 to -1.74$)$. However, if bedroom ED placement was accompanied by the corresponding restriction, its harmful effect did not 
Table 1 Characteristics of the study participants $(n=556)$

n (\%)/mean (SD)

\begin{tabular}{|c|c|}
\hline \multicolumn{2}{|l|}{ Sex, n (\%) } \\
\hline Female & $288(51.80)$ \\
\hline Male & $268(48.20)$ \\
\hline Age, mean (SD), years & $5.46(0.70)$ \\
\hline \multicolumn{2}{|l|}{ District, $\mathrm{n}(\%)$} \\
\hline Hong Kong Island & $254(45.68)$ \\
\hline Yuen Long & $302(54.32)$ \\
\hline \multicolumn{2}{|l|}{ Number of EDs the family owned, mean (SD) } \\
\hline Television & $1.45(0.73)$ \\
\hline Computer & $1.96(0.93)$ \\
\hline Tablet computer & $0.55(0.59)$ \\
\hline Smartphone & $1.31(0.91)$ \\
\hline Game console & $0.51(0.72)$ \\
\hline Portable game console & $0.58(0.78)$ \\
\hline \multicolumn{2}{|l|}{ Placement of ED in child's bedroom, $n(\%)$} \\
\hline Any & $164(29.50)$ \\
\hline Television & $99(17.81)$ \\
\hline Computer & $114(20.50)$ \\
\hline Game console & $16(2.88)$ \\
\hline \multicolumn{2}{|l|}{ Parental restriction of ED use, $n(\%)$} \\
\hline All EDs & $398(71.58)$ \\
\hline Television & $447(80.40)$ \\
\hline Desktop/laptop computer & $462(83.09)$ \\
\hline Game console & $451(81.12)$ \\
\hline \multicolumn{2}{|l|}{ Parent-child interaction score, mean (SD) (range: 0-3) } \\
\hline Recreation-based & $1.86(0.61)$ \\
\hline Learning-based & $2.04(0.66)$ \\
\hline Sleep duration, mean (SD), hours & $9.41(1.04)$ \\
\hline \multicolumn{2}{|l|}{ School readiness, mean (SD) } \\
\hline CEDI total score (range: $0-50$ ) & $43.55(5.57)$ \\
\hline CEDI physical well-being (range: $0-10$ ) & $8.99(1.06)$ \\
\hline CEDI social competence (range: $0-10$ ) & $8.40(1.68)$ \\
\hline CEDI emotional maturity (range: $0-10$ ) & $8.35(1.29)$ \\
\hline CEDI language and cognitive skills (range: $0-10$ ) & $9.29(1.22)$ \\
\hline $\begin{array}{l}\text { CEDI communication and general knowledge } \\
\text { (range: } 0-10 \text { ) }\end{array}$ & $8.53(1.87)$ \\
\hline
\end{tabular}

CEDI is a teacher-reported assessment for school readiness.

Median (IQR) of the continuous variables were presented in online supplementary table 1.

CEDI, Chinese Early Development Instrument; ED, electronic device.

reach a statistically significant level $(\beta-0.54,95 \% \mathrm{CI}-1.59$ to $0.51)$. The detailed results on ED-specific and domain-specific analyses can be found in online supplementary table 2 .
Table 3 Spearman correlations between ED use, family SES, parentchild interaction and sleep duration

\begin{tabular}{|c|c|c|c|c|}
\hline & Family SES & $\begin{array}{l}\text { Recreation- } \\
\text { based parent- } \\
\text { child interaction }\end{array}$ & $\begin{array}{l}\text { Learning-based } \\
\text { parent-child } \\
\text { interaction }\end{array}$ & $\begin{array}{l}\text { Sleep } \\
\text { duration }\end{array}$ \\
\hline \multicolumn{5}{|l|}{ Family ownership } \\
\hline Television & -0.04 & 0.05 & 0.08 & 0.07 \\
\hline Computer & -0.02 & -0.04 & -0.05 & -0.04 \\
\hline Tablet computer & $0.28 * * *$ & 0.16 & 0.10 & 0.00 \\
\hline Smartphone & 0.10 & 0.14 & 0.13 & 0.11 \\
\hline Game console & -0.08 & 0.10 & 0.02 & 0.04 \\
\hline $\begin{array}{l}\text { Portable game } \\
\text { console }\end{array}$ & $-0.31 * * *$ & -0.05 & 0.01 & 0.02 \\
\hline \multicolumn{5}{|c|}{ Placement in the child's bedroom } \\
\hline Any of below & -0.18 ** & 0.00 & 0.00 & -0.03 \\
\hline Television & -0.18 ** & 0.01 & 0.02 & -0.03 \\
\hline $\begin{array}{l}\text { Desktop/laptop } \\
\text { computer }\end{array}$ & -0.12 & -0.01 & -0.02 & -0.04 \\
\hline Game console & -0.10 & 0.01 & 0.02 & -0.01 \\
\hline \multicolumn{5}{|c|}{ ED placed in the bedroom without corresponding parental restriction } \\
\hline Any of below & $-0.22 * * *$ & $-0.16^{*}$ & -0.10 & -0.05 \\
\hline Television & $-0.21 * * *$ & $-0.16^{*}$ & -0.10 & -0.06 \\
\hline $\begin{array}{l}\text { Desktop/laptop } \\
\text { computer }\end{array}$ & -0.14 & -0.09 & -0.05 & -0.05 \\
\hline Game console & -0.08 & -0.18 ** & -0.11 & -0.02 \\
\hline
\end{tabular}

${ }^{*} \mathrm{p}<0.05,{ }^{* *} \mathrm{p}<0.01,{ }^{* * *} \mathrm{p}<0.0001$

ED, electronic device; SES, socioeconomic status.

\section{Mediation analysis}

ED variables' correlation with potential mediators are shown in table 3. Recreation-based parent-child interaction was negatively associated with $\mathrm{ED}$ bedroom placement without restriction $(r=-0.16, p<0.05)$. ED variables were not significantly associated with learning-based parent-child interaction and sleep duration, which were not included in the subsequent path analysis.

The potential pathway between school readiness and bedroom ED placement without parental restriction is shown in figure 1. Numbers shown next to the arrows were the path coefficients. After mutual adjustment, recreation-based parent-child interaction ( $\beta 1.01,95 \% \mathrm{CI} 0.23$ to 1.80$)$ and $\mathrm{ED}$ placed in the bedroom without restriction $(\beta-1.39,95 \% \mathrm{CI}-2.20$ to -0.58$)$ were associated with overall school readiness. Accounting for both pathways, ED placed in the bedroom were harmful to preschoolers' overall school readiness $(\beta-2.70,95 \% \mathrm{CI}-3.40$ to -2.01$)$. The mediated (indirect) effect of recreation-based parent-child interaction was significant $(\beta$ $-1.31,95 \% \mathrm{CI}-1.92$ to -0.69$)$ and the variable alone explained

Table 2 Effect of placing electronic devices in children's bedroom on school readiness

\begin{tabular}{|c|c|c|c|c|c|c|c|c|}
\hline & \multicolumn{2}{|l|}{ Any ED } & \multicolumn{2}{|l|}{ Television } & \multicolumn{2}{|c|}{ Desktop/laptop computer } & \multicolumn{2}{|l|}{ Game console } \\
\hline & $\beta(95 \% \mathrm{Cl})$ & $\mathrm{p}$ & $\boldsymbol{\beta}(95 \% \mathrm{Cl})$ & $\mathrm{p}$ & $\beta(95 \% \mathrm{Cl})$ & $\mathrm{p}$ & $\boldsymbol{\beta}(95 \% \mathrm{Cl})$ & $\mathrm{p}$ \\
\hline Physical & $-0.12(-0.26$ to 0.01$)$ & & $-0.37(-0.59$ to -0.14$)$ & ** & $-0.05(-0.27$ to 0.17$)$ & & $-0.05(-0.56$ to 0.46$)$ & \\
\hline Social & $-0.29(-0.50$ to -0.08$)$ & ** & $-0.49(-0.84$ to -0.14$)$ & ** & $-0.28(-0.62$ to 0.06$)$ & & $-0.94(-1.74$ to -0.15$)$ & * \\
\hline Emotional & $-0.19(-0.35$ to -0.03$)$ & * & $-0.29(-0.55$ to -0.02$)$ & * & $-0.22(-0.48$ to 0.04$)$ & & $-0.39(-0.99$ to 0.21$)$ & \\
\hline Language/cognitive & $-0.24(-0.39$ to -0.10$)$ & ** & $-0.46(-0.71$ to -0.21$)$ & $* * *$ & $-0.20(-0.43$ to 0.04$)$ & & $-0.39(-0.95$ to 0.16$)$ & \\
\hline Communication/general & $-0.26(-0.50$ to -0.03$)$ & * & $-0.52(-0.92$ to -0.13$)$ & ** & $-0.18(-0.56$ to 0.21$)$ & & $-0.78(-1.68$ to 0.11$)$ & \\
\hline Total & $-1.11(-1.80$ to -0.42$)$ & ** & $-2.13(-3.27$ to -0.98$)$ & $* * *$ & $-0.93(-2.05$ to 0.20$)$ & & $-2.56(-5.18$ to 0.05$)$ & \\
\hline
\end{tabular}

${ }^{*} \mathrm{p}<0.05,{ }^{* *} \mathrm{p}<0.01,{ }^{* * *} \mathrm{p}<0.001$.

Adjusted for sex and family socioeconomic status using multiple regression.

School readiness measured using Chinese Early Development Instrument. Total: total score; Physical: physical well-being; Social: social competence; Emotional: emotional maturity; Language/cognitive: language and cognitive skills; communication: communication and general knowledge; total: total school readiness.

$E D$, electronic device. 

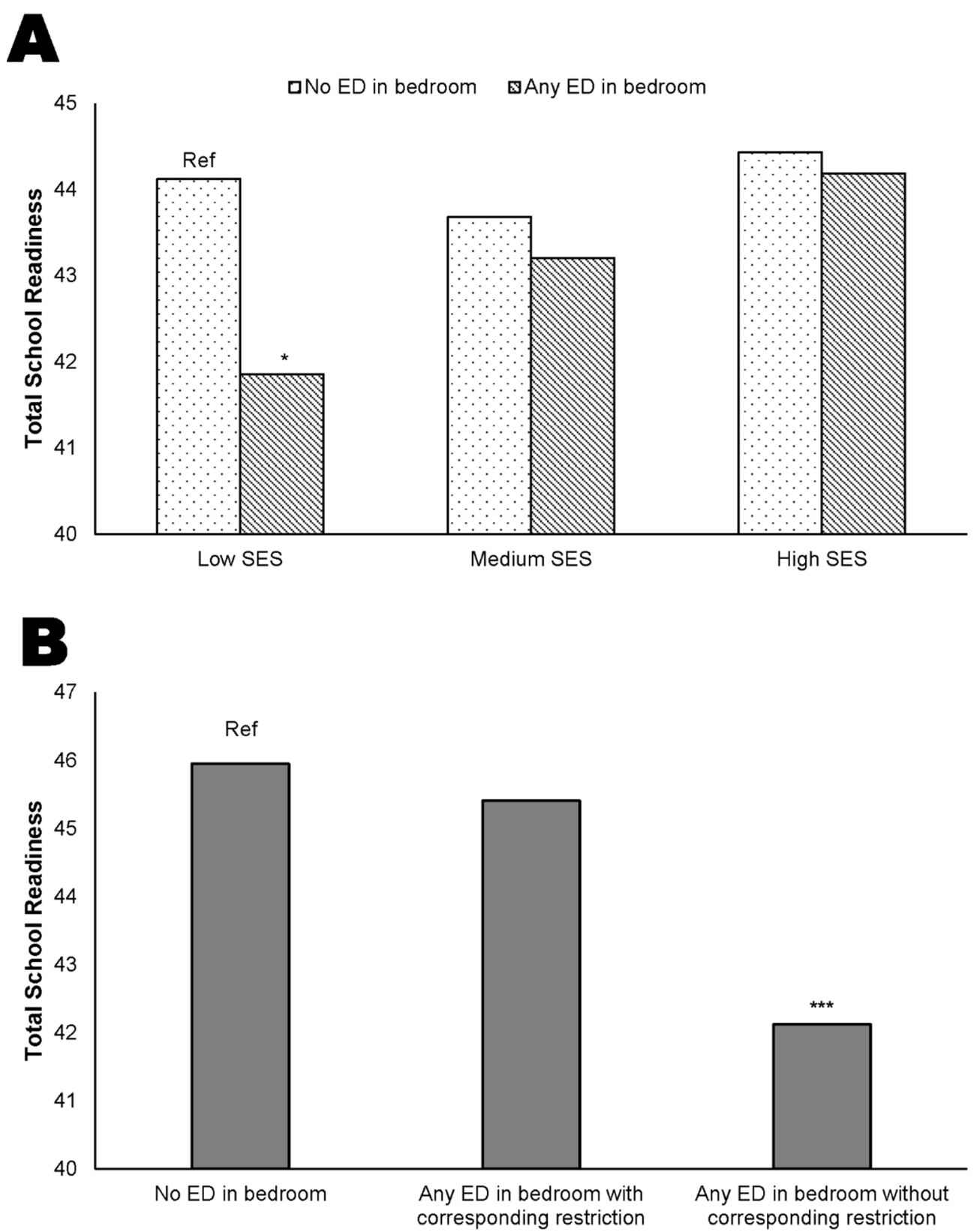

Figure 2 (A) Effect of bedroom electronic device (ED) placement on school readiness moderated by family socioeconomic status (SES). (B) Effect of bedroom ED placement on school readiness moderated by parental restriction. Adjusted for sex and family SES. ${ }^{*} p<0.05,{ }^{* * *} p<0.001$. Ref, reference group for comparison.

$48.5 \%$ of the association. There was still a significant proportion $(51.5 \%)$ of the association that remained unexplained.

\section{DISCUSSION}

The impact of ED on child development, particularly among preschoolers who are more susceptible to environmental influence, was unclear. The present study enriches our understanding about how bedroom ED placement could affect children's school readiness and highlights the importance of parental restriction. School readiness is a holistic measure of child development at about 5 years of age. Even though the present study could not ascertain the long-term effects of early use of EDs, school readiness was found to be associated with later developmental outcomes, such as mathematics and language test scores. ${ }^{2324}$ Our local cohort study in Hong Kong also found that the CEDI predicts children's academic performance, psychosocial well-being and behavioural problems in the long run. These highlight the importance of school readiness, and the harm of placing EDs in the children's bedroom could be substantial.

Previous studies found that placing a television in a child's bedroom was associated with poor academic performance, ${ }^{25}$ sleeping problems ${ }^{26}{ }^{27}$ and higher risk of obesity. ${ }^{97}$ Echoing with these evidence, we found that the placement of a television in a young child's bedroom resulted in poor developmental outcomes. In addition, attention should be paid to game console's effect on young children's social development. Reduction in 0.94 point over a 10 -point scale $(\sim 10 \%)$ is already alarming but the problem could be even more far-reaching. A large-scale longitudinal study has found that the initial social competence of youths could strongly predict whether they would have video gaming addiction-a severe condition which could greatly reduce their future social skills. ${ }^{28}$ Therefore, to avoid initiating this vicious 
cycle, parents of young children should be very cautious about proper placement of game consoles.

Parental restriction of ED use was found to partially alleviate the negative effect of bedroom ED placement. The moderating effect reflects the direct reduction in media exposure and also indicates the reception of more educational media content. Parents who practised restrictive mediation generally had better awareness towards media content and were more likely to choose educational and more constructive media content for their children. ${ }^{29}$

The reduction in parent-child interaction was found to be a significant mediator between unrestricted bedroom ED placement and children's school readiness. This observation is supported by the theory of displacement, which states that excessive and unrestricted media use would displace children's engagement in other interactive and learning activities. ${ }^{30}$

Although technology has been regarded as the 'The Great Equalizer ${ }^{31} 32$ to bridge the developmental gap between wealthier and poorer children, our study showed an opposite conclusion. Families from lower SES were more likely to place ED in the child's bedroom and children from lower SES families suffered more from the harmful effect of bedroom ED placement. Our findings are consistent with studies conducted in other regions. ${ }^{33} 34$ The exact reasons behind this phenomenon are not well understood, but one possible reason was that parents with higher SES were more capable of choosing educational media content which may benefit child development. ${ }^{35}$ On the other hand, parents with lower SES tend to use EDs as a means to keep their children occupied and often are not aware of the media content. ${ }^{36}$ Exposure to non-educational media content may increase the risk of subsequent attentional problems. ${ }^{35}$ As socioeconomic disparity in early childhood development is a serious global issue ${ }^{12}$ policy-makers should be alerted whether advanced technology would further widen gap between the rich and the poor.

There are several limitations in this study. First, children in this study were recruited from two districts, which may not be representative of the general population. Nevertheless, the sample provided a socioeconomically diverse data set, which allowed us to study the influence of SES on ED use. Second, this is a cross-sectional study and the causality between improper ED use and lower school readiness cannot be guaranteed. However, based on the literature and clinical experience, it seems unlikely that parents of young children will place ED in the children's bedroom because of their lower school readiness. Third, the self-reported data from parents could be subject to recall bias and social desirability bias. Parents may under-report the placement of EDs in their child's bedroom if they perceive this as a violation of the social norm. Finally, this study did not collect information on the media content, the context in which children interacted with EDs and the quality of childcare, which may affect interpretation of the results. Last but not least, the CIs in table 2 were relatively wide. This indicates that the true effect for ED bedroom placement could be less substantial as shown in the point estimates. Nevertheless, we should also note that the interval estimates appear narrower after accounting for parental restriction (see online supplementary table 2), suggesting that the less precise CIs in table 2 could be due to unaccounted moderators.

\section{CONCLUSION}

Placing ED in the children's bedroom was associated with lower school readiness but parental restriction of children's ED use could help to alleviate the harmful effect. Such harmful effect was particularly prominent among children from lower SES families, and was partially mediated by less recreation-based parent-child interactive activities. Future studies on this topic should consider a comprehensive measurement related to children's media exposure, including usage pattern and media content.

Correction notice This paper has been amended since it was published Online First. Owing to a scripting error, some of the publisher names in the references were replaced with 'BMJ Publishing Group'. This only affected the full text version, not the PDF. We have since corrected these errors and the correct publishers have been inserted into the references.

Acknowledgements We thank the developer of the EDI, Dr Magdalena Janus and the Offord Centre for Child Studies at McMaster University, for allowing us to use the EDI in this study. We also thank the kindergartens, children and their parents for participating in this study.

Contributors K-WF contributed to the study design, data interpretation and drafted the manuscript. FKWH analysed and interpreted the data, drafted the manuscript and is the co-first author. NR contributed to the study conceptualisation and data interpretation, critically reviewed the manuscript and is the co-corresponding author of this manuscript. FJ interpreted the data and critically reviewed the manuscript. SLL contributed to the study design and critically reviewed the manuscript. TM-CL and $\mathrm{SH}-\mathrm{sC}$ interpreted the data and critically reviewed the manuscript. MEY contributed to the study conceptualisation and data interpretation and critically reviewed the manuscript. PI designed the study, interpreted the data, critically reviewed the manuscript and is the corresponding author of this manuscript. All authors approved the final manuscript as submitted.

Competing interests None declared.

Ethics approval Institutional Review Board of the University of Hong Kong/ Hospital Authority Hong Kong West Cluster.

Provenance and peer review Not commissioned; externally peer reviewed.

(c) Article author(s) (or their employer(s) unless otherwise stated in the text of the article) 2017. All rights reserved. No commercial use is permitted unless otherwise expressly granted.

\section{REFERENCES}

1 Vanderloo LM. Screen-viewing among preschoolers in childcare: a systematic review. BMC Pediatr 2014;14:205.

2 O' Keeffe GS, Clarke-Pearson K. Council on Communications and Media. The impact of social media on children, adolescents, and families. Pediatrics 2011;127:800-4.

3 Wright JC, Huston AC, Murphy KC, et al. The relations of early television viewing to school readiness and vocabulary of children from low-income families: the early window project. Child Dev 2001;72:1347-66.

4 Mistry KB, Minkovitz CS, Strobino DM, et al. Children's television exposure and behavioral and social outcomes at 5.5 years: does timing of exposure matter? Pediatrics 2007;120:762-9.

5 Pagani LS, Fitzpatrick C, Barnett TA, et al. Prospective associations between early childhood television exposure and academic, psychosocial, and physical well-being by middle childhood. Arch Pediatr Adolesc Med 2010;164:425-31.

6 Tomopoulos S, Dreyer BP, Berkule S, et al. Infant media exposure and toddler development. Arch Pediatr Adolesc Med 2010;164:1105-11.

7 Duch $\mathrm{H}$, Fisher EM, Ensari I, et al. Association of screen time use and language development in Hispanic toddlers: a cross-sectional and longitudinal study. Clin Pediatr 2013:52:857-65.

8 Carson V, Kuzik N, Hunter $\mathrm{S}$, et al. Systematic review of sedentary behavior and cognitive development in early childhood. Prev Med 2015;78:115-22.

9 Dennison BA, Erb TA, Jenkins PL. Television viewing and television in bedroom associated with overweight risk among low-income preschool children. Pediatrics 2002; 109:1028-35.

10 Cain N, Gradisar M. Electronic media use and sleep in school-aged children and adolescents: a review. Sleep Med 2010;11:735-42.

11 Christakis DA. The effects of infant media usage: what do we know and what should we learn? Acta Paediatr 2009;98:8-16.

12 Ip P, Rao N, Bacon-Shone J, et al. Socioeconomic gradients in school readiness of Chinese preschool children: The mediating role of family processes and kindergarten quality. Early Child Res Q 2016;35:111-23.

13 Tso W, Rao N, Jiang F, et al. Sleep Duration and School Readiness of Chinese Preschool Children. J Pediatr 2016;169:266-71.

14 Forget-Dubois N, Lemelin J-P, Boivin M, et al. Predicting Early School Achievement with the EDI: a Longitudinal Population-Based Study. Early Educ Dev 2007:18:405-26.

15 Silburn SR, Brinkman S, Lawrence D, et al. P1-151 establishing the construct and predictive validity of the australian Early Development Index (AEDI). Early Hum Dev 2007;83:\$125 
16 Janus M, Offord DR. Development and psychometric properties of the early development instrument (EDI): a measure of children's school readiness. Can J Behav Sci 2007;39:1-22.

17 Ip P, Li SL, Rao N, et al. Validation study of the Chinese Early Development Instrument (CEDI). BMC Pediatr 2013;13:146.

18 Vyas S, Kumaranayake L. Constructing socio-economic status indices: how to use principal components analysis. Health Policy Plan 2006;21:459-68.

19 Ip P, Tso W, Rao N, et al. Rasch Validation of the Chinese Parent-Child interaction Scale (CPCIS). World J Pediatr (Epub ahead print: 2017).

20 Sadeh A. A brief screening questionnaire for infant sleep problems: validation and findings for an internet sample. Pediatrics 2004;113:e570-7.

21 Hooper D, Coughlan J, Mullen MR. Structural equation modelling: guidelines for determining model fit. EJBRM 2008;6:53-60.

22 Oberski D. lavaan.survey: An $R$ Package for Complex Survey Analysis of Structural Equation Models. J Stat Softw 2014:57:1-27.

23 Brinkman S, Gregory T, Harris J, et al. Associations between the Early Development Instrument at Age 5, and Reading and Numeracy skills at Ages 8, 10 and 12: a Prospective Linked Data Study. Child Indic Res 2013;6:695-708.

24 Forget-Dubois N, Lemelin J-P, Boivin M, et al. Predicting early school achievement ith the EDI: a longitudinal population-based study. Early Educ Dev 2007; 18:405-26.

25 Borzekowski DL, Robinson TN. The remote, the mouse, and the no. 2 pencil: the household media environment and academic achievement among third grade students. Arch Pediatr Adolesc Med 2005:159:607-13.
26 Garrison MM, Liekweg K, Christakis DA. Media use and child sleep: the impact of content, timing, and environment. Pediatrics 2011;128:29-35.

27 Chahal H, Fung C, Kuhle S, et al. Availability and night-time use of electronic entertainment and communication devices are associated with short sleep duration and obesity among Canadian children. Pediatr Obes 2013:8:42-51.

28 Gentile DA, Choo H, Liau A, et al. Pathological video game use among youths: a twoyear longitudinal study. Pediatrics 2011;127:e319-29.

29 Barkin S, Ip E, Richardson I, et al. Parental media mediation styles for children aged 2 to 11 years. Arch Pediatr Adolesc Med 2006;160:395-401.

30 O'Connor BD. Childhood development and media use: a literature review of the effects of media on children's physical and psychosocial development. Washington: College of Nursing, Washington State University-Spokane, 2012.

31 Wyer K. The Great Equalizer: assistive Technology launches a New Era in Inclusion. Teaching Tolerance 2001;19:25-9.

32 Hancock A. Technology: the great equalizer. Community Coll J 2001;72:16-21.

33 Zimmerman FJ, Christakis DA, Meltzoff AN. Television and DVD/video viewing in children younger than 2 years. Arch Pediatr Adolesc Med 2007;161:473-9.

34 Christakis DA, Ebel BE, Rivara FP, et al. Television, video, and computer game usage in children under 11 years of age. J Pediatr 2004;145:652-6.

35 Zimmerman FJ, Christakis DA. Associations between content types of early media exposure and subsequent attentional problems. Pediatrics 2007;120:986-92.

36 Lareau A. Invisible Inequality: social Class and Childrearing in Black families and White families. Am Sociol Rev 2002:67:747-76. 